\section{Decifra-me ou te devoro! Estado, capital e a urgência do debate crítico na Saúde Coletiva}

\author{
Áquilas Mendes \\ Universidade de São Paulo, Faculdade de Saúde Pública, \\ São Paulo, SP, Brasil. \\ <aquilasmendes@gmail.com>
}

Leonardo Carnut

Universidade Federal de São Paulo, Centro de Desenvolvimento de Ensino Superior em Saúde, São Paulo, SP, Brasil

<leonardo.carnut@gmail.com>

http://dx.doi.org/10.1590/1981-7746-sol00168

DANTAS, André V. Do socialismo à democracia: tática e estratégia na Reforma Sanitária Brasileira. Rio de Janeiro: Editora Fiocruz, 2017, 319p.

Em tempos de tantos embates no movimento do capital contemporâneo, sob o comando do capital fictício, e seus reflexos perversos nas políticas sociais, em geral, e na saúde, em particular, promover uma reflexão crítica radical acerca dos rumos do Movimento da Reforma Sanitária Brasileira (MRSB) constitui tarefa intelectual e política fundamental para traçar os desafios da Saúde Coletiva. Essa possibilidade certamente é materializada por meio do livro de André Dantas.

A grande contribuição desse autor referese à crítica a respeito da estratégia tomada pela Reforma Sanitária a partir da década de 1990. O movimento perdeu sua radicalidade - reivindicando o socialismo - e tentou assegurar os ganhos obtidos nos anos anteriores, insistindo no pleito da cantilena democrática burguesa (Marx, 2012). Porém, esse movimento optou seguir o caminho institucional do reformismo, defendendo um sistema de proteção social, desvinculado dos ideais antagônicos que o forjaram até a década de 1980 .

Sobre esta situação, o trabalho de Dantas nos remete a uma indagação que permanece central na contemporaneidade, essencialmente para todos os que defendem a saúde pública no país: é possível apostar na construção institucional, ou seja, promover reformas no Estado Social, ${ }^{1}$ como forma de superação da crise atual na saúde?

Historicamente, a esquerda sanitária veio trilhando apenas a institucionalidade das 'reformas' por iludirem-se com a ideia de que o
Estado social existente possa estar a serviço da produção do 'bem comum' (Correia, 2015). Em nossa percepção, aproximada à visão de André Dantas, um passo promissor na constatação dos limites do Estado é reavivar, na memória da Saúde Coletiva, sua 'intrincada' relação com o modo de produção capitalista.

Para entender a dinâmica da crise capitalista e seus efeitos na saúde, consideramos importante, antes de tudo, (re)decifrar a natureza do Estado capitalista. Em última, instância, o Estado constitui expressão de uma sociabilidade determinada, assumindo as relações de poder e de exploração nas condições capitalistas. A assunção disso remete à análise do capital como uma relação social de produção - uma 'forma social' - e como a 'forma política' (estatal) que se associa a essa dinâmica (Hirsch, 2017). Por isso, desconsiderar que o Estado brasileiro, na medida em que é parte integrante das relações capitalistas de produção e sua consonância com a dinâmica mundial do capital, é um deslize crasso e que pôs em risco toda estratégia e tática delineada pelo Movimento da Reforma Sanitária até hoje.

Trata-se, então, de considerar que a relação Estado/capital é orgânica. Neste sentido, não existe separação (nem relativa, que dirá absoluta!) entre o Estado e o capital. Apoia-se aqui na contribuição do debate alemão da derivação do Estado dos anos 1970 que deduz a 'forma jurídica/política' (Estado), ou 'forma contratual' das contradições da dinâmica do capital. Esta relação atribui ao Estado sua natureza capitalista, assegurando a troca das mercadorias na sua forma-valor e a própria exploração da força de trabalho (Bonnet e Piva, 2017).

Cabe mencionar, nessa reflexão, principalmente a ilusão do processo atravessado pela Reforma Sanitária, a esfinge que os reformistas subestimaram, que nosso autor Dantas se debruçou de forma profícua e que Pachukanis ${ }^{2}$ nos ajuda a desmitificar sua essência.

Dantas inicia seu livro explicitando o argumento de Hirsch em que "a maneira pela qual o Estado age para assegurar a reprodução é determinada, em seu conteúdo, pelo movimento do capital e pelas lutas de classe e, em sua forma, pela sua transposição ao nível do aparelho de Estado" (Hirsch apud Dantas, 2017, p. 20). Desse modo, o raio de manobra da burguesia para promover sacrifícios vem se reduzindo, e daí a dificuldade de manter presente a aposta política em relação 
ao caráter emancipatório da democracia burguesa. É justamente nesse contexto que Dantas indica a retomada do debate tático-estratégico de classe, essencialmente da classe trabalhadora dos anos 1970 para os dias atuais, tendo como central o processo político construído ao redor do Movimento da Reforma Sanitária, no sentido de avaliar os seus desdobramentos.

A tese central do livro polemiza com o que o autor considera o processo de absolutização da democracia no contexto de luta de classes daquele período, compreendida como 'valor universal' (Coutinho, 1979), isto é, aspecto nodal da estratégia sanitária e que serviu para que ela fosse 'devorada'. Dantas adverte que "tal processo em torno da fetichização da democracia" expressa uma divinização ou, sendo fiel a suas palavras, "a absolutização do Estado na consecução da tática do movimento sanitário pela reforma do sistema de saúde" (p. 24). Nessa perspectiva, Dantas não poupa críticas: "a centralidade que crescentemente ganhou a questão democrática deslocou o verdadeiro debate estratégico em nome do socialismo, uma vez que - fosse para promover a autocrítica da esquerda; fosse para lutar contra a ditatura; fosse, enfim, para lutar pelo socialismo - o caminho a percorrer parecia ser o mesmo" (p. 24).

Na primeira parte do livro, o autor concede especial atenção a um panorama teórico-político sobre o Estado e a questão democrática segundo a tradição marxista. De forma geral, nos mostra como Marx e Engels elaboram sua crítica ao Estado burguês, indicando o descaso da burguesia com a questão democrática conforme o avanço das forças produtivas e a imposição de sua dominação no contexto do acirramento da luta de classes. No âmago dessa disputa, Dantas não deixa de ilustrar na base de discussão do papel do Estado, na tradição marxista na virada do século XIX, o debate sobre mais reforma e menos revolução, capitulado pela social-democracia alemã, resvalando em resquícios sobre o pensamento da esquerda marxista, em geral e da esquerda sanitária, em particular.

No segundo capítulo, Dantas se aproxima do debate brasileiro sobre a questão democrática, em sintonia com a temática da revolução. Nessa discussão, percorre o caminho que vai das principais questões ancoradas nas interpretações da formação social brasileira, acerca das quais havia se construído a Estratégia Democrática Nacional (EDN) à elaboração da Estratégia Democrática-Popular (EDP). É dada ênfase a crítica de Caio Prado Jr., Florestan Fernandes e Carlos Nelson Coutinho à primeira Estratégia e, posteriormente, como esse último autor foi privilegiado pelo Movimento da Reforma Sanitária e influenciado nos esboços da nova estratégia das classes trabalhadoras que viria a ter no Partido dos Trabalhadores (PT) a sua mais forte vocalização.

Entre vários aspectos nessa discussão, Dantas nos possibilita a compreensão de que o MRSB abandonou a crítica importante de Florestan Fernandes à reflexão profunda do papel e da função do Estado capitalista brasileiro. Dantas destaca a ideia-síntese de Florestan em seu clássico, $A$ revolução burguesa, de que “o Estado não só era incontornavelmente de classe, capturado precipuamente pelos interesses imperialistas e de suas burguesias locais" (...) "como atuava de fato como comitê executivo da burguesia, sem espaços para concessões, uma vez que sob um registro dependente" (p. 113).

Por sua vez, o MRSB priorizou o ensaio de 1979 de Carlos Nelson Coutinho, intitulado "A democracia como valor universal", em que para além de fazer a crítica à estratégia etapista democrática-nacional, possibilitava as linhas gerais do que viria a ser a EDP liderada pelo PT - esquerda democrática - na década de 1980 e a mola-mestra da trajetória priorizada pelo movimento sanitário: o caminho institucional das reformas por dentro do Estado.

Na segunda parte do livro, Dantas explora as características estruturais e o sentido mais geral da Reforma Sanitária, desde sua ação nos anos 1970 até a atualidade. Destaque é dado às lutas travadas no campo da saúde em que tiveram prioridade a atuação pelo enfrentamento setorial em relação à luta mais ampla no âmbito da sociabilidade das relações capitalistas. Daí o autor mencionar a prioridade da estratégia sanitária se fazer muito mais pela via da institucionalidade, por um lado, e por outro, pela reclamação constante da ausência da classe trabalhadora na defesa de sua agenda.

Dantas chama a atenção, nessa parte, para o destacado papel do Centro Brasileiro de Estudos de Saúde (Cebes) e da Associação Brasileira de Saúde Coletiva (Abrasco) - ambas instituições nascidas na década de 1970 - na formulação das concepções e táticas do MRSB. O legado dessas 
instituições marcou os desafios conjunturais e os posicionamentos estratégicos assumidos pelo movimento. Nesse sentido, Dantas nos lembra, não por coincidência, o famoso documento do Cebes de 1979: "A questão democrática na área da saúde" (p. 182). Assim, o autor nos mostra que, nesse ambiente de 'programa democrático', o Estado passa a ser lócus preterido para desempenhar papel decisivo na formulação tático-estratégica que se desenhava no interior do MRSB. Por isso, Dantas insiste na ideia do "empenho dos sanitaristas na tática institucional de ocupação de postos na máquina estatal" (p. 183) nesse período.

Integra, ainda, nesta parte do livro, a importância a respeito da agenda democrática do movimento sanitário, nos anos 1970, por meio da pauta prioritária do Movimento Popular em Saúde (MOPS) e que foi elemento de destaque na $8^{a}$ Conferência Nacional de Saúde, na Comissão Nacional da Reforma Sanitária e na Assembleia Nacional Constituinte: a questão da participação social. Essa discussão Dantas desenvolve no capítulo 4, sob a forma de uma indagação provocativa, "Reeducar o Estado?". O objetivo desse pleito foi o de se enfrentar a herança patrimonialista e clientelista da formação do Estado brasileiro, tendo como diretriz a institucionalização do 'controle social' na saúde, por meio dos conselhos de saúde nos três níveis de gestão do SUS. Dantas faz um balanço crítico desse mecanismo de democratização do Estado, evidenciando que o resultado do 'controle social', até os dias atuais, se resumiu a um processo altamente institucionalizado, distante da força de luta da classe trabalhadora. O autor chama a atenção para o caráter problemático da atuação desses conselhos.

No quinto e último capítulo, intitulado "Reforma Sanitária, SUS e socialismo: questão de princípios", Dantas insiste na análise do debate estratégico da Reforma Sanitária, alertando para os riscos de suas formulações estratégicas que, por um lado, valorizavam a democracia burguesa, mas, por outro, se afastavam do reconhecimento do caráter capitalista do Estado. Aqui, o destaque do autor é para o desconhecimento dos fatores limitantes da forma e função dessa estratégia sanitária que acabou reforçando a ideia-síntese, 'saúde é democracia' (que até hoje é lema em congressos da Abrasco, por exemplo) e também para o não reconhecimento dos obstáculos de sua realização no interior da lógica do modo de produção capitalista.

Na conclusão, o autor discute alguns aspectos que contribuem para uma reflexão mais geral sobre a crise em que o movimento sanitário se encontra, conjuntamente com a dita 'esquerda democrática'. Daí o título dessa parte ser extremamente provocador: "Da democracia ao socialismo". Não resta dúvida, nesta parte, que Dantas reconhece os resultados devastadores que a contraofensiva neoliberal provocou a partir da década de 1990, principalmente contribuindo para o esvaziamento do debate estratégico da esquerda brasileira, mas também não escapa de sua análise a fragilidade dos desafios apontados para a luta por essa 'esquerda democrática', especialmente no contexto de pósparticipação de seus quadros-chave nos postos de comando do governo federal. Dantas delimita bem sua síntese: “O essencial é o deslocamento que ela promoveu, ou pretendeu promover, da centralidade do socialismo para a centralidade da democracia" (p. 281). Para caminhar no sentido contrário, Dantas nos oferece uma alternativa: "Mais do que nunca é preciso que afirmemos que a democratização burguesa não se constitui como alternativa ao socialismo" (p. 282).

O mais importante para a reflexão acerca dos desafios do movimento sanitário é que Dantas não deixa, em nenhum momento, de articular muito bem a necessidade de um debate estratégico que se apoie firmemente numa crítica ao capital e suas formas de exercício de dominação, mantendo presente o socialismo no discurso e na prática democrática. Sem dúvida, trata-se de um livro essencial para ampliar o horizonte do campo da saúde coletiva e que instiga a autocrítica sem desqualificar o empenho dos sanitaristas na luta política do perverso tempo social em que se encontravam. Contudo, ainda assim, isso não nos exime de repensar as estratégias e táticas sobre o alcance de uma outra sociedade. Portanto, não há como fazer isso sem encarar o Estado como 'a grande Esfinge'. Se não soubermos decifrála politicamente, seremos fatalmente devorados mais uma vez. 


\section{Notas}

${ }^{1}$ A denominação 'Estado Social' se apoia em Boschetti (2016), que busca captar a regulação econômico-social por meio de políticas sociais, atribuindo ao Estado capitalista suas determinações objetivas, explicitando que a incorporação dessas políticas pelo Estado não extrai dele sua característica essencialmente capitalista.

${ }^{2}$ Evguiéni B. Pachukanis, jurista soviético, escreveu na década de 1920 seu livro Teoria Geral do Direito e Marxismo, desenvolvendo uma ideia original no interior do pensamento marxista no tocante ao papel do direito e do Estado na sociedade capitalista e póscapitalista. O autor propõe uma investigação sobre o direito com base no método da obra de maturidade de Marx e que se refere especialmente ao texto de $\mathrm{O}$ capital. Para mais informações, ver Pachukanis (2017).

\section{Referências}

BONNET, Alberto; PIVA, Adrián. Prólogo. In: BONNET, Alberto; PIVA, Adrián. (Compiladores). Estado y capital: el debate alemán sobre la derivación del Estado. Ciudad Autónoma de Buenos Aires: Herramienta, 2017.

BOSCHETTI, Ivanete. Assistência social e trabalho no capitalismo. São Paulo: Cortez, 2016.

CORREIA, Marcus O. G. Por uma crítica imanente sobre os limites das políticas públicas de direitos sociais e o Estado na produção do bem comum no modo de produção capitalista. Saúde e Sociedade, São Paulo, v. 24, n. S1, p. 55-65, 2015.

COUTINHO, Carlos N. A democracia como valor universal. In: SILVEIRA, Ênio. Encontros com a Civilização Brasileira. Rio de Janeiro: Civilização Brasileira, 1979. p. 33-47.

HIRSCH, Joachim. Elementos para una teoría materialista del Estado. In: BONNET, A; PIVA, A. (Compiladores). Estado y capital: el debate alemán sobre la derivación del Estado. Ciudad Autónoma de Buenos Aires: Herramienta, 2017.
KARL, Marx. Crítica ao Programa de Gotha. São Paulo: Boitempo, 2012.

PACHUKANIS, Évgueni. A teoria geral do direito e o marxismo e ensaios escolhidos (1921-1929). São Paulo: Sundermann, 2017. 